This item was submitted to Loughborough's Research Repository by the author.

Items in Figshare are protected by copyright, with all rights reserved, unless otherwise indicated.

\title{
Mathematical morphology-based local fault detection in DC Microgrid clusters
}

PLEASE CITE THE PUBLISHED VERSION

https://doi.org/10.1016/j.epsr.2020.106981

PUBLISHER

Elsevier

VERSION

AM (Accepted Manuscript)

\section{PUBLISHER STATEMENT}

This paper was accepted for publication in the journal Electric Power Systems Research and the definitive published version is available at https://doi.org/10.1016/j.epsr.2020.106981.

LICENCE

CC BY-NC-ND 4.0

\section{REPOSITORY RECORD}

Bayati, Navid, Hamid Reza Baghaee, Amin Hajizadeh, Mohsen Soltani, and Zhengyu Lin. 2020.

"Mathematical Morphology-based Local Fault Detection in DC Microgrid Clusters". Loughborough University. https://hdl.handle.net/2134/13530866.v1. 


\section{Mathematical Morphology-based Local Fault Detection in DC Microgrid Clusters}

Navid Bayati ${ }^{*}$, , Hamid Reza Baghaee ${ }^{2}$, Amin Hajizadeh ${ }^{1}$, Mohsen Soltani ${ }^{1}$, and Zhengyu Lin ${ }^{3}$

\footnotetext{
${ }^{1}$ Department of Energy Technology, Aalborg University, Denmark

${ }^{2}$ Department of Electrical Engineering, Amirkabir University of Technology, Tehran, Iran

${ }^{3}$ Wolfson School of Mechanical, Electrical and, Manufacturing Engineering, Loughborough University, U.K
}

Abstract - A new local current-based fast high impedance fault (HIF) detection scheme for DC microgrid clusters using mathematical morphology (MM) is proposed in this paper. The proposed strategy consists of two MM based parts. The first part is MM erosion filtering to extract the current signals and its components to extract the differential 11 feature vector. The second part is MM regional maxima, for defining a determinative value to detect faults in a line segment by the lowest possible time. This scheme also uses local measured values to eliminate the need for communication channels, which provide a low cost, reliable, and fast fault detection method for DC microgrid clusters.

Moreover, to provide an accurate HIF detection method, the accurate HIF model in DC systems is presented and used in the proposed method. For demonstrating the efficiency, authenticity, and compatibility of the proposed method, digital time-domain simulations are carried out in MATLAB/Simulink environment under different scenarios such as overload, noise, low and HIFs to distinguish between overloads and HIFs, and the results are compared with several strategy's accuracy and speed under different conditions.

Nomenclature

$\begin{array}{ll}\text { AC } & \text { Alternating current, } \\ \text { RES } & \text { Renewable energy source, } \\ \text { LIF } & \text { Low-impedance fault, } \\ \text { HIF } & \text { High impedance fault, } \\ \text { MM } & \text { Mathematical morphology, } \\ \text { WT } & \text { Wind turbine, } \\ R_{d c} & \text { The resistance of DC line, } \\ L_{d c} & \text { The inductance of DC line, } \\ C & \text { The capacitance of the converter's capacitor, } \\ I_{0} & \text { Normal current, } \\ V_{0} & \text { Normal voltage, } \\ t_{0} & \text { Fault time, } \\ t_{1} & \text { The end time of capacitor discharge stage, } \\ t_{0} & \text { Operation time of breaker, } \\ t_{d} & \text { Delay of measurements, } \\ \text { MCT } & \text { maximum clearing time, } \\ R & \text { The equivalent resistance of HIF, } \\ V_{D C} & \text { Voltage rating, } \\ i & \text { Fault current, } \\ k & \text { Arc constant, } \\ N & \text { Total number of samples, }\end{array}$




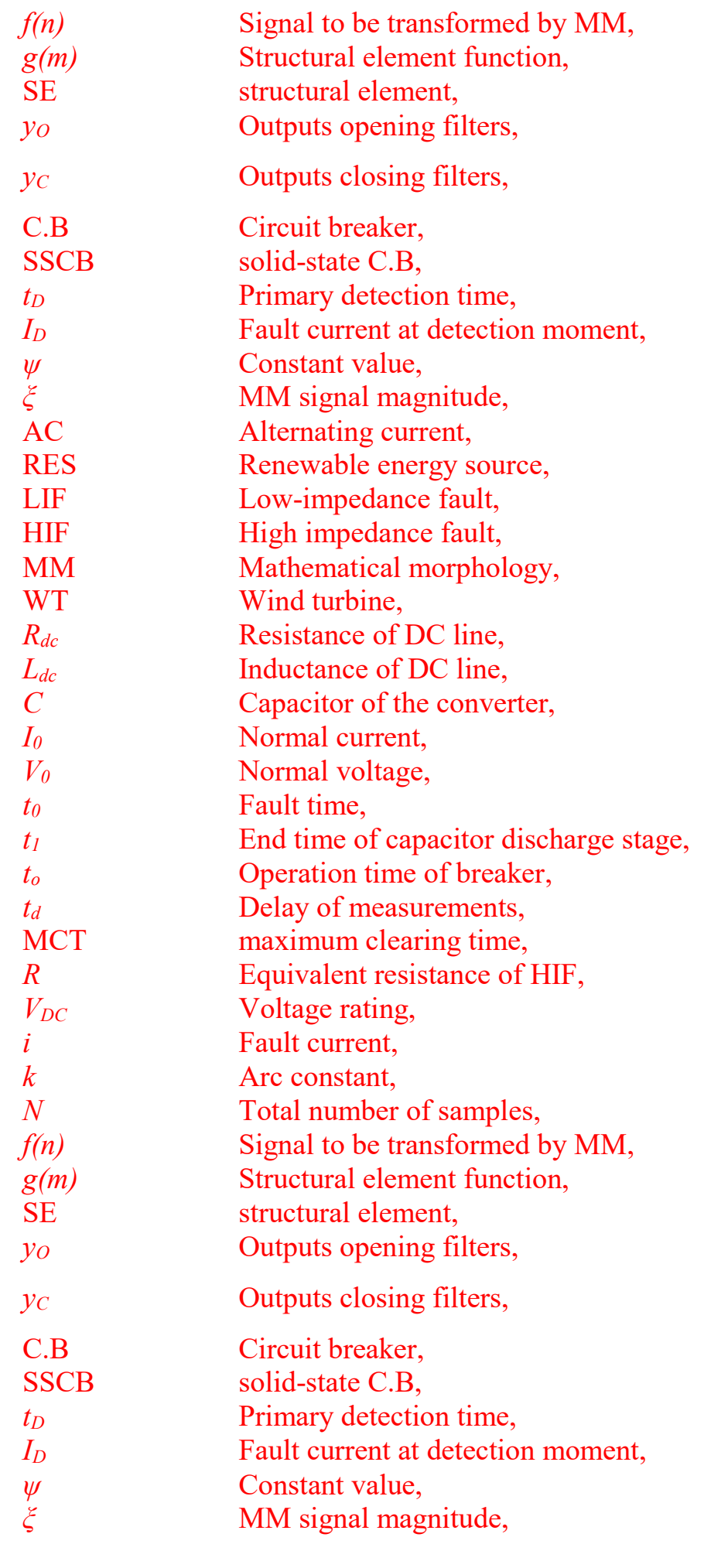

I. INTRODUCTION

3 DC Microgrid applications are increased in recent years due to the development of power electronic technologies, 4 renewable energies, energy storage, and DC loads usage. Compared with AC systems, DC microgrids have the 5 advantages of fewer power conversion stages and higher reliability and efficiency [1]-[2]. However, the utilization of 6 DC systems provides new challenges in terms of protecting the DC network during faults, due to the high penetration 
of RESs, power electronic converters, and the absence of zero-crossing points in DC systems [3].

In recent years, to improve DC microgrids' reliability, the concept of DC microgrid cluster is proposed. In a DC microgrid cluster, multiple DC microgrids are connected to neighbor DC microgrids and/or the main AC grid to reduce the investment cost and improve reliability [4]. Due to the connecting of several DC Microgrids with high penetration of RESs, more point of couplings, and longer transmission lines, compared with the single DC microgrid, the protection of the DC microgrid cluster is more complicated, and the mutual power flow among DC microgrids need to be considered [5]. Also, the DC Microgrid cluster performances are usually not considered at the design stage of a protection scheme.

One of DC systems' main equipment for tripping the fault current is C.B, and due to the lack of zero-crossing point in DC systems, the traditional AC C.Bs cannot be implemented directly in these systems. Several schemes are suggested for DC C.Bs to isolate the DC lines during faults in [6]-[8]. In [6], a Thomson coil-based fast C.B for medium voltage DC systems. The designing of the C.B is optimized by circuit parameters and geometric dimensions of components. Moreover, one of the main challenges in designing DC C.Bs is operation time, thus, in [7], an ultrafast medium-voltage hybrid DC C.B consists of three switching devices, silicon carbide emitter turn-off thyristor as the main isolator, a mechanical switch, and a commutating switch to quickly turn the primary current to the main isolator for arc less interruption. In [8], the node currents' behavior under DC faults and their natural response is analyzed more specifically. A protection system is designed based on protective devices that included hybrid circuit breakers and relays. These protective devices monitor local measures to detect and isolate DC faults as quickly as possible.

In terms of fault detection of DC microgrid clusters, LIFs can be detected and cleared rapidly due to the high transient fault current by discharging of capacitors of converters, which could damage the freewheeling diodes of converters within a few milliseconds [9]. Moreover, one of the possible fault types is HIFs in DC systems, which have low fault current magnitude, and may cause the fault detection failure [10]. Consequently, DC microgrids' fault detection scheme should be equipped with both of the LIFs and HIFs detection functionalities.

Several research types have been performed on the fault characteristic analysis and fault detection methods in DC microgrids. In DC Microgrids, the fault current has a high rise and magnitude characteristic, and the DC/DC and $\mathrm{AC} / \mathrm{DC}$ converters are vulnerable to this high amplitude fault current [11]. Therefore, DC microgrids must be equipped with fault detection and isolation schemes. In terms of detecting faults, non-unit protection methods based on undervoltage and overcurrent have been discussed in [11]-[14], which use different methods. However, they have limited functionality during HIFs. In [15], a fault detection scheme is proposed for islanded DC microgrid clusters using the threshold in the value of fault current. However, this method cannot detect HIFs and has low-speed performance during LIF detection. In the studies mentioned above, the transient behavior of HIFs has not been extensively considered, which causes a difference between the simulation and practical results. Also, the fault detection strategies and adjusting the value of threshold are very difficult to set, and reliable and fast fault detection to avoid damage to converters cannot be guaranteed.

The current derivative has also been investigated as a fault detection factor in DC microgrids in [16]. However, this method is vulnerable to noise, sampling rate, and a small delay could cause a high difference between the measured 
and actual value of fault current derivative. Also, it could be difficult to implement in DC microgrids due to the low line impedance. Communication-based fault detection strategies such as directional and current differential methods are suggested in [17], [18] to high selectivity, and fault detection device speed. However, due to the additional utilizing devices for communication infrastructure, higher cost, failure possibility, and delay are involved than local-based fault detection approaches. The studies mentioned above cannot guarantee the detection of HIFs due to the low magnitude of HIF currents. Although many methods have been implemented on the HIF detections, they have been designed based on conventional AC systems or cannot meet DC microgrids' appropriate speed and reliability requirements [19].

The HIF detection schemes for DC and AC Microgrids are investigated in [20]-[22]. In [20], a method based on a discrete wavelet transform of current is presented for detecting HIFs of distribution systems. However, it is not reliable in different system conditions. In [21] and [22] the heuristic methods based on artificial neural network for HIF detection is suggested, which require complex computations and implementation. However, these strategies did not provide a cost-effective and satisfactory protection scheme during HIF on DC systems.

This paper takes advantage of using MM, in which different features of signals caused by electricity system disturbances are extracted to distinguish different conditions of the system with high accuracy. MM uses morphological operators, which are fast and simple and applicable to non-periodic high-frequency signals. Therefore, MM provides an accurate and reliable signal component extraction method without any distortion. In [20], MM and erosion filters are used to detect a microgrid's islanded mode within a short period. The transient phenomena of the power system, caused by RLC circuits and switching instruments, are quickly detected by MM in [24] even when the transients are very close to each other.

The studies mentioned above reveal that the HIF and LIF detection in DC systems is still an unsolved challenge. The lack of research in the protection of DC Microgrid clusters motivates to propose a fast fault detection method for these systems. Moreover, due to MM's advantages in feature extractions, utilizing a MM regional maxima-based fault detection scheme improves the performance of fault detection methods. Therefore, in this paper, an advanced local and MM-based fault detection scheme in DC microgrid clusters can be applied for both HIF and LIF. The proposed scheme uses a fast fault detection feature using MM based filters to detect the faults before damaging the freewheeling diodes of converters during the fault without requiring any communication links.

The rest of this paper is organized as: the characteristics of faults in DC microgrid clusters are analyzed in section II. In section III, based on fault current features, the MM based fault detection scheme and framework of the utilization of the scheme are proposed. The simulation and experimental test results of the proposed scheme are described in section IV. Finally, the conclusions of the paper are presented in section V.

\section{FAUlt CHARACTERISTICS OF DC MICROGRID CLUSTERS}

\section{A. Basics of DC microgrid clusters}

With the development of advanced power electronic devices and converters, the efficient transfer of DC electricity to DC-based loads has more possibilities. Fig. 1 presents the test DC microgrid cluster of this paper, and the parameters of the system are represented in Table 1. Each DC microgrid has different RES technologies, loads, and power values. Due to the system's DC structure, more power can be transmitted through the DC lines than the AC systems with the 
1 same voltage rating. Furthermore, utilizing DC power reduces the number of power conversion stages; for example, 2 WTs require $\mathrm{AC} / \mathrm{DC}$ and $\mathrm{DC} / \mathrm{AC}$ converters for connecting to AC systems; however, in DC microgrids, WTs only 3 requires an $\mathrm{AC} / \mathrm{DC}$ converter. Therefore, it reduces power losses and costs and improves system efficiency.

4 The DC microgrid clusters usually contain a DC/DC converter to connect two neighboring DC microgrids and an $\mathrm{AC} / \mathrm{DC}$ converter to connect to the AC main grid. For DC microgrid clusters, different fault current characteristics with high magnitude are anticipated. Therefore, a new fault detection scheme should be established by considering the characteristics of both HIFs and LIFs in the DC microgrid clusters

TABLE 1 SYSTEM PARAMETERS

\begin{tabular}{|c|c|}
\hline Component & Rating \\
\hline Line lengths (km) & Line $_{1}=1$, Line $_{2}=1$, Line $_{3}=0.5$, Line $_{4}=0.5$ \\
\hline $\begin{array}{l}\text { Inductance and } \\
\text { resistance }\end{array}$ & $R=10 \mathrm{~m} \Omega / \mathrm{km}, L=0.05 \mathrm{mH} / \mathrm{km}$ \\
\hline Nominal Voltage & $480 \mathrm{~V}$ \\
\hline \multirow[t]{3}{*}{ DC Microgrid $_{1}$} & WT: $200 \mathrm{~kW}$, Reactance: $3.23 \Omega$ \\
\hline & Fuel cell: $100 \mathrm{~kW}$, Ohmic loss per cell: $0.000328 \Omega$, number of cells: 1000 \\
\hline & Battery: $200 \mathrm{Ah}, 0.1 \Omega$ \\
\hline \multirow[t]{2}{*}{ DC Microgrid 2} & WT: $200 \mathrm{~kW}$, Reactance: $3.23 \Omega$ \\
\hline & Fuel cell: $100 \mathrm{~kW}$, Ohmic loss per cell: $0.000328 \Omega$, number of cells: 1000 \\
\hline DC Microgrid ${ }_{3}$ & Battery: $200 \mathrm{Ah}, 0.1 \Omega$ \\
\hline
\end{tabular}

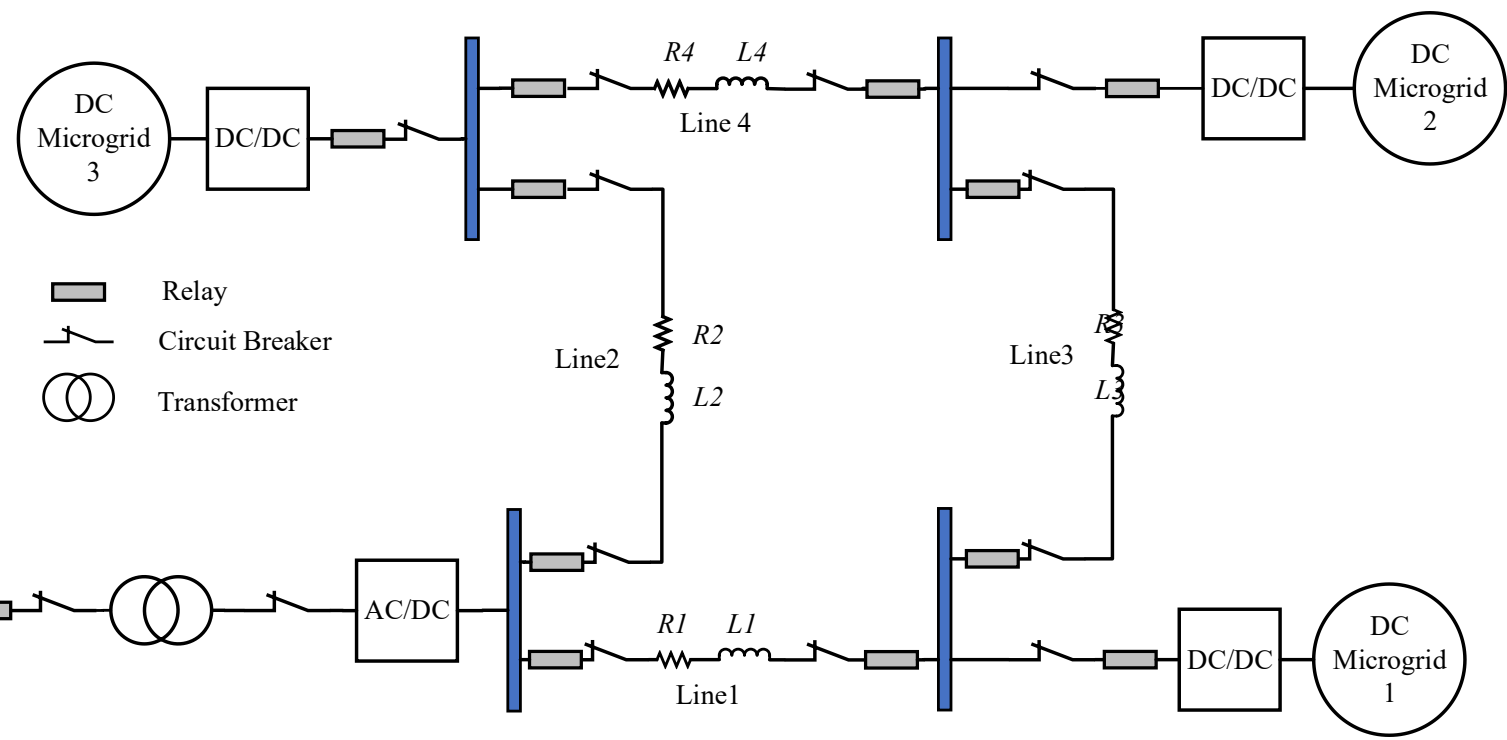

Fig. 1. DC Microgrid cluster test network 
An analysis of the response of the DC microgrid cluster during LIF is provided in this section. In terms of fault current magnitude and rise time, a LIF is generally considered the most serious condition for converters. The equivalent circuit of $\mathrm{AC} / \mathrm{DC}$ and DC/DC converters are depicted in Fig. 2. During fault in DC systems, the fault current passes through two states. The first state is capacitor-discharge, and the natural response of an RLC circuit due to the DC-link capacitor's discharge immediately after the fault. The second stage starts when the capacitor's voltage becomes less than the maximum voltage input, and the fault current reaches its magnitude. It results in the participation from converter interface sources to the faulty node. During the capacitor-discharge, the capacitor starts discharging through cable impedance by the occurrence of a fault, and the waveform is shown in Fig. 3. The peak current has resulted during the discharging of the DC link capacitor. Its magnitude goes around several times of the system's rated current without the operation of any fault detection devices. The second state of fault current is with a freewheeling diode paralleled with the converter's active devices. This state starts after dropping the voltage across the DC link capacitor to zero or negative value. As an effect, the voltage of the converter terminal is reversed, and the diode starts conducting. The current response changes due to this alternative path irrespective of the IGBT conducting state. During a fault, AC/DC converters immediately cut off the IGBT switches to self-protect, and DC link capacitors behave like a DC source. Thus, the DC link capacitors discharge a current to the fault location exponentially decaying as (1) through the path depicted in Fig. 2(a). It should mention that, in (1)-(5), for the case of AC/DC converter, the value of $R_{d c}, L_{d c}$, and $C$ should be replaced by $R_{1}, L_{1}$, and $C_{1}$, as shown in Fig. 2 (a), respectively, and for the case of DC/DC converter of Fig. 2 (b), the value of $R_{d c}, L_{d c}$, and $C$ should be replaced by $R_{2}, L_{2}$, and $C_{2}$, as shown in Fig. 2 (b), respectively. The voltage and current of the capacitor discharge stage can be obtained by [25]:

$$
\begin{aligned}
& V_{C}=\frac{V_{0} w_{0}}{w} e^{-a t} \sin (m+b)-\frac{I_{0}}{w C} e^{-a t} \sin (w) \\
& I_{\text {fault }}=C \frac{d v_{C}}{d t}=-\frac{I_{0} w_{0}}{w} e^{-a t} \sin (w-a)+\frac{V_{0}}{w L} e^{-a t} \sin w \\
& t_{1}=t_{0}+(p-/) / w
\end{aligned}
$$

21 where

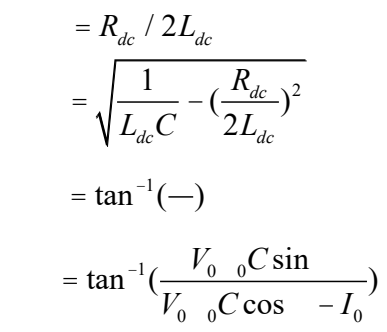

where, $R_{d c}$ and $L_{d c}$ are the resistance and inductance between converter and fault location, respectively. Then, during the second stage, the fault current starts to flow through the freewheeling diodes, after the dropping capacitor voltage to zero, due to the cut-off of the IGBTs. Therefore, the fault current is calculated by

$$
I_{\text {fault }}=I_{0} e^{-\left(\frac{R_{d c}}{L_{d c}}\right) t}
$$


where $I_{0}$ is the initial value of fault current at $t_{1}$ [25], in this stage, due to the high-rise current of LIFs, diodes might be damaged. Consequently, the fault should be detected within $t_{1}$, before reaching the capacitor's voltage to zero to avoid diodes' damage. Therefore, it can be concluded that LIFs should be fast seen because the voltage of the capacitor drops to zero within a few milliseconds.

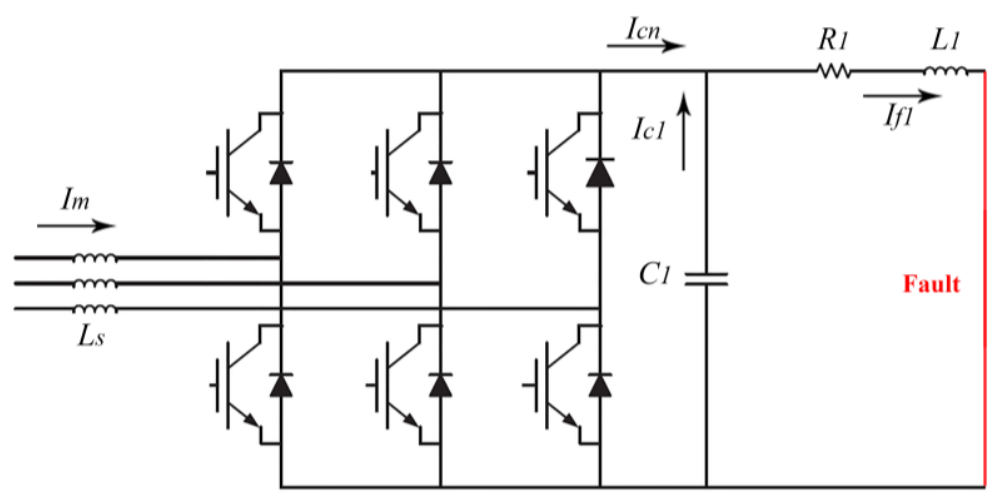

,
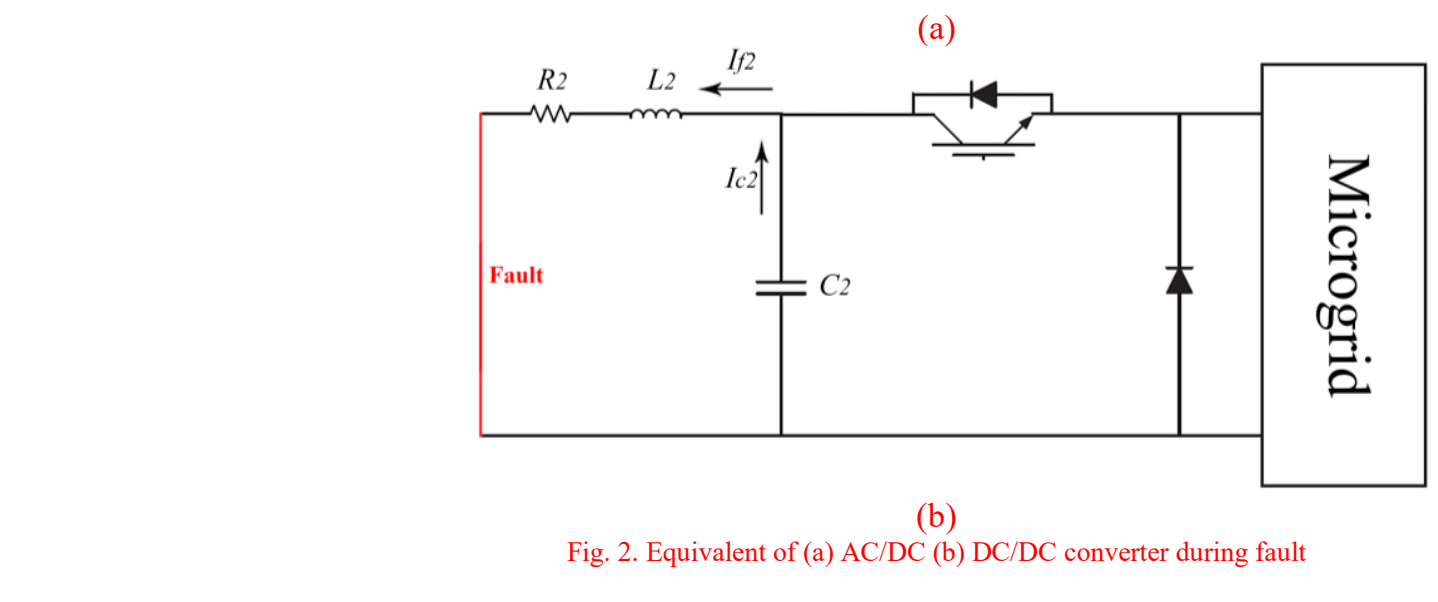

(b)

Fig. 2. Equivalent of (a) AC/DC (b) DC/DC converter during fault

In terms of the DC/DC converter contribution, the equivalent circuit is illustrated in Fig. 2(b). The corresponding voltage and current $\mathrm{DC} / \mathrm{DC}$ and $\mathrm{AC} / \mathrm{DC}$ converter equations are the same during the fault, as presented in (1) to (5). However, because the AC/DC converter's filter size is much larger than DC/DC converters, the fault current contribution of the AC/DC converter would be more than DC/DC converter. Therefore, based on the transient behavior of converters in DC microgrid clusters, the fault should be detected quickly to avoid damages to diodes under the condition. The MCT can be used as an index to determine the performance of the protection method. The value of MCT is defined as

$$
M C T=t_{1}-t_{0}-t_{O}-t_{d}
$$

Therefore, a fault detection scheme should detect a fault of less than MCT to guarantee converters' safety. Fig. 3 represents the different fault current stages of a DC system. As shown in Fig. 3, the fault current reaches its maximum value during the capacitor discharge stage. Then after a few milliseconds, the current flows through the freewheeling diodes. 


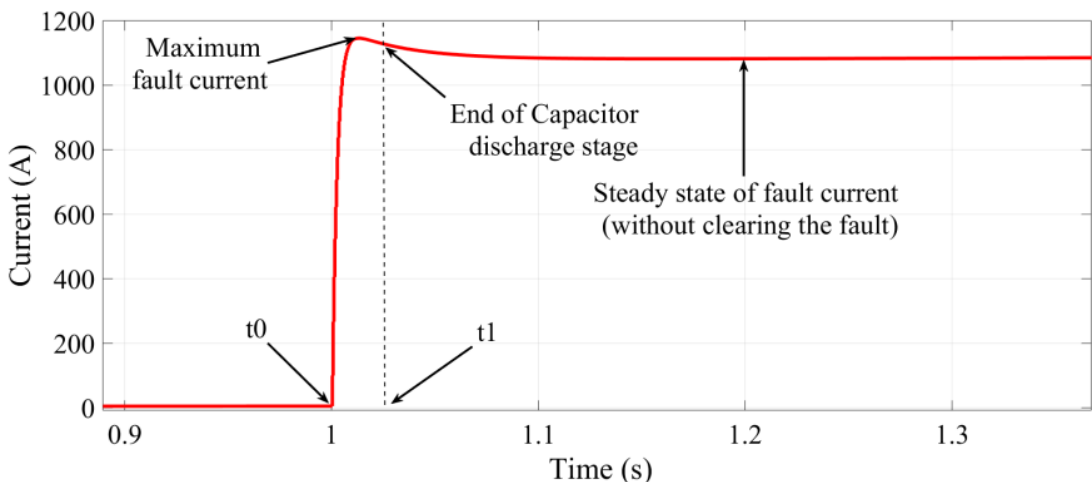

Fig. 3. Fault current in the DC Microgrid cluster.

C. HIF characteristics in DC microgrid clusters

When a conductor approaches close to another conductor or ground through a high resistance, a HIF arcing will occur. Due to the low value of fault current during HIF, detecting this small magnitude fault current is a challenging task. If a HIF remains in the system for a long time, it results in repetitive re-ignition and extinction [26]. The HIFs are very complex phenomena and illustrate a highly nonlinear performance. The characteristic of a HIF is divided into three stages, buildup, shoulder, and nonlinearity. In the buildup, the fault current rises to the maximum value at the first stage; then, the buildup ceases in the shoulder stage. The nonlinearity stage refers to the nonlinear behavior of HIFs. The model of HIFs in DC systems has been considered rarely. The model of [28] is utilized in this paper to accurately considers the performance of HIFs. The performance of HIFs can be modeled by

$$
\begin{aligned}
& \text { ë } \\
& \hat{i} i_{j+1}=i_{j}-\frac{R i_{j}+k / i_{j}^{1.2}+35-V_{D C} \sin m}{R-1.2 k / i_{j}^{2.2}} \\
& \hat{\imath} 2 n p+p / 3<m<2 n p+2 p / 3 \quad n=0,1,2, \ldots
\end{aligned}
$$

Therefore,

$$
R=\frac{1.2 k i_{j+1} / i_{j}^{2.2}-1.2 k / i_{j}^{2.2}-k / i_{j}^{1.2}-35+V_{D C} \sin w}{i_{j+1}}
$$

The equation (7) is used laboratory observations, and the constant value of $k$ can be calculated by experimental tests for different HIFs in different situations. In this paper, the value of $k$ is considered as 27000 by laboratory tests and observations. The fault current of the presented model is shown in Fig. 4. As shown in the figure, the fault current has repetitive behavior with a small change in the current magnitude. In this paper, the HIF is modeled by a nonlinear resistor using (8) and inputs of current and voltage. In this paper, this model is considered to detect the HIFs in DC microgrid clusters.

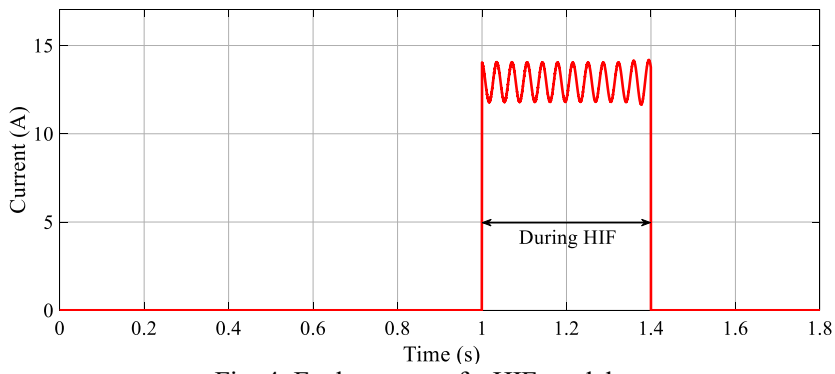

Fig. 4. Fault current of a HIF model. 
MM is developed in [28] as a nonlinear time-domain signal processing tool. Despite the frequency-domain signal processing tools such as Fourier transform and wavelet, which are periodic, the MM applies to non-periodic signals and does not require any integral transforms. Furthermore, MM operators have fast and straightforward calculations without using any division and multiplication operations, unlike the frequency-domain signal processing tools. In the DC systems, the only available quantity of current is the magnitude. Thus, the frequency-domain signal processing tools are not suitable for DC systems, and MM is more effective in DC systems.

MM has two fundamental transformations, erosion and dilation. Erosion is a shrinking procedure, as defined in (9),

and dilation is considered as a swelling procedure, as presented by [29]

$$
\begin{aligned}
& y_{E}(n)=(f \ominus g)(n)=\min (f(n+m)-g(m)) \\
& \quad 0 \leq(n+m) \leq N, m \geq 0 \\
& y_{D}(n)=(f \oplus g)(n)=\max (f(n-m)+g(m)) \\
& \quad 0 \leq(n-m) \leq N, m \geq 0
\end{aligned}
$$

$\mathrm{SE}$ is the foundation of MM transformation and is a probe for the extraction of the transient signal features [30]. The length, height, and shape of the SE affect the MM transformation results. Therefore, the selection of SEs should be made based on the MM application.

Based on erosion and dilation, the basics of the MM filter are calculated by (9). The MM filter's opening and closing concept refers to the sharping edge and narrowing valleys and gaps, respectively. Opening and closing filters are defined by

$$
\begin{aligned}
& y_{O}(n)=(f \circ g)(n)=((f \ominus g) \oplus g)(n) \\
& y_{C}(n)=(f \cdot g)(n)=((f \oplus g) \ominus g)(n)
\end{aligned}
$$

B. MM regional maxima

The function of MM regional maxima sends the regional maxima values to fault detection devices to compare these values with the threshold. The value of the threshold indicates the border between overload and fault conditions. Therefore, the threshold is selected for an overload condition by $20 \%$ more in normal load current. Within the first and milliseconds of fault, the fault current starts to rise to a high value. Therefore, the values of MM regional maxima start to increase faster than the fault current measured value. The MM regional maxima are all higher than any current magnitude in its finite number of neighborhoods. They can be computed from the residue of the h-maxima of height 1. The h-maxima transformation suppresses any domes with a height smaller or equal than a threshold level and decreases the other domes' height by the threshold level. It is defined as the reconstruction by dilation of $f$ subtracted by a height of threshold level. Consequently, it causes the fault detection before reaching a maximum of fault current within a few milliseconds. Also, this method can detect the fault before the maximum value of fault current, which could guarantee the safety of converters.

\section{DC fault current detection}

MM-based erosion filter can extract the transient features of the fault current signal and remove the noises from the 
main signal. The output of the MM-based erosion filter is the input of the MM regional maxima. As depicted in Fig. 5, the fault detection function immediately detects the fault before the fault current reaches to freewheeling diode stage. Therefore, fast detection is possible before the fault current's peak time, which avoids any damages to the converter and freewheeling diodes. Also, it provides more time for C.Bs' operation due to the low detection time of the MMbased fault detection method. Also, by utilizing SSCBs, the fault isolation device's operation time is low, and due to the lack of communication link, the delay is avoided in signals.

Based on Fig. 5, the MM regional maxima signal changes to a high value more quickly than the fault current signal. Therefore, this signal can be sent directly to the SSCBs for tripping. With the help of erosion filer and low-pass filtering characteristic, this method is less vulnerable to signal noise. Moreover, the exact time of the fault does not require to be detected. Fig. 6 illustrates the diagram of the proposed scheme for fault detection on DC microgrid clusters. The scheme only requires the current of the one end of a line segment, which eliminates the communication link between measurement devices of both ends of a line.

On the other hand, selectivity is an essential function in fault detection systems, which capable of the protection system only operates during fault at their protection zone. For this aim, in this paper, an additional factor should be added to each fault detection system's operation time. By increasing distance from fault location, the fault magnitude will decrease. Therefore, the closer protection device senses a higher magnitude in fault current and should operate by lower time than other protection devices. Thus, the operation time of each protection device is calculated and sent to SSCBs by

$$
t=t_{D}+\frac{x y}{I_{D}}
$$

In this paper, $\psi$ is assumed 10000. In (13), due to the low value of $\xi$, the range of additional term is around several microseconds. The value of $\xi$ is based on the MM magnitude, and therefore it is approximately less than 25 $10^{-9}$ of $I_{D}$. Therefore, it cannot cause a significant delay in the operation time of SSCBs; however, it makes an appropriate selectivity for the proposed protection system.

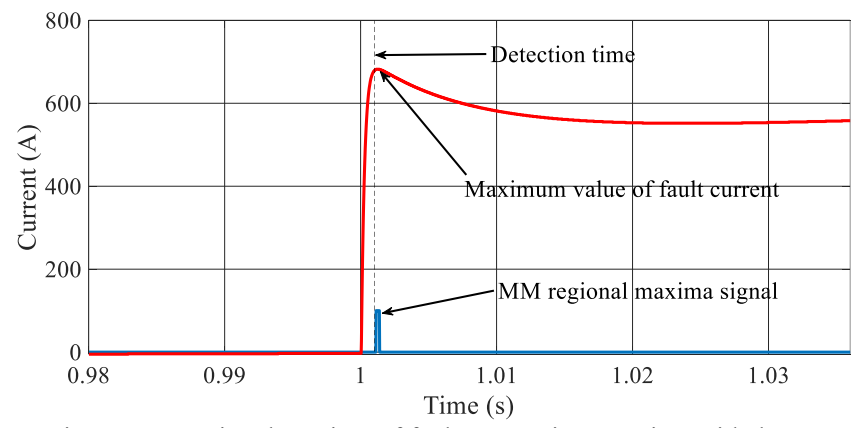




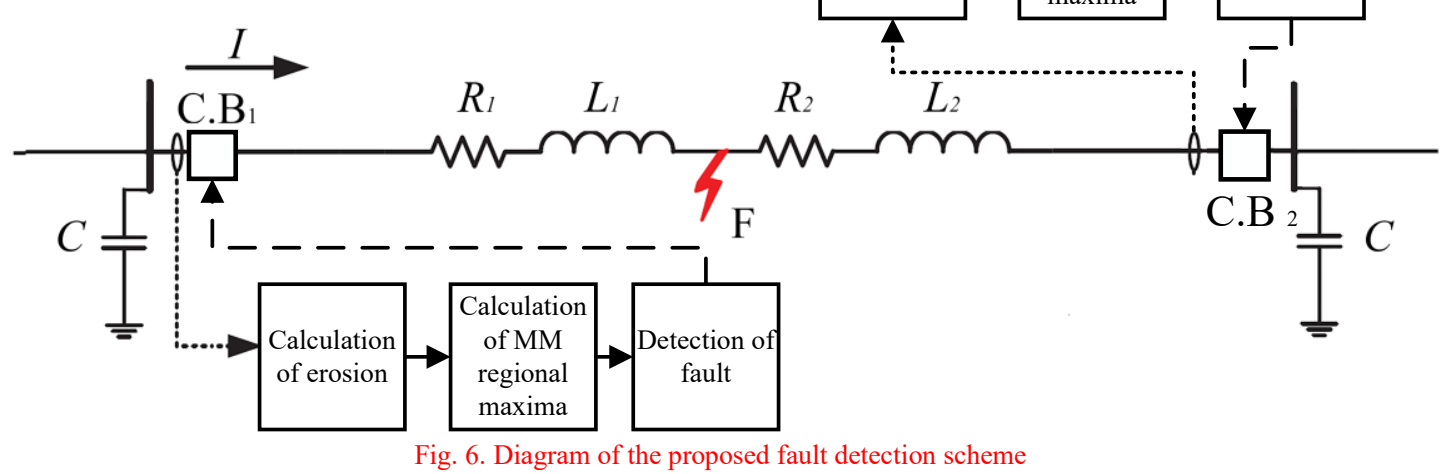

\section{HIF fault detection}

As discussed previously, the proposed fault detection strategy can be used to detect the fault before the peak time of fault current. However, based on Fig .4, the HIF current has a repetitive and spiky performance. Fig. 7 represents the operation of the proposed method during HIF. As mentioned before, based on (8), the fault current has spiky and repetitive characteristics by a small change in the magnitude of the fault current. Based on this figure, the fault is detected immediately after occurring the fault, and it is independent of the small change of the fault current during HIF. Therefore, this method does not need any function for distinguishing LIFs and HIFs.

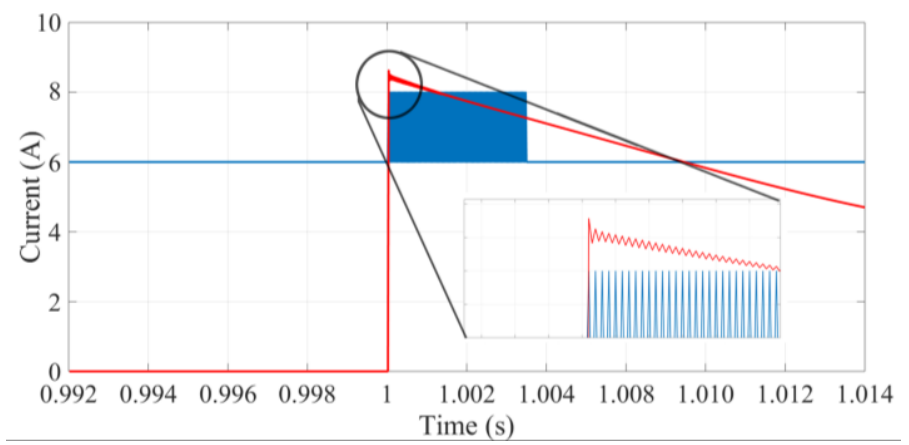

Fig. 7. Fault current and the fault detection signal during HIF

\section{SIMULATION AND EXPERIMENTAL RESULTS}

For verifying the proposed fault detection scheme's performance, the test DC microgrid cluster system shown in Fig. 1 with parameters of Table 1 is modeled in MATLAB/Simulink and implemented experimentally. The MM-based relay is located on one side of each line segment to detect the faults. Then, each line only requires one measurement device at the relay side with the sampling rate of $50 \mathrm{kHz}$. Relays are connected to SSCBs at both sides of the line segments. In case of selection of sampling rate, although the higher sampling rate provides more current samples and accurate results, it requires more cost on the installation of sensors. Therefore, based on [31], in DC systems, the accuracy of fault protection methods for sampling rate from $25 \mathrm{kHz}$ to $100 \mathrm{kHz}$ is almost constant. Therefore, in this paper, the sampling rate of $50 \mathrm{kHz}$ is selected for sensors. 


\section{A. Simulation results}

Fig. 3 represents the fault current of Line $_{1}$ during a LIF that occurs at $t=1 \mathrm{~s}$ on the middle of the line segment with fault resistance of $0.1 \Omega$. The fault causes a high-rise capacitive discharge current at the first milliseconds of the fault stage. Based on the fault location and resistance, the magnitude and time to reach a maximum of fault current are varied, and the corresponding MCTs are shown in Table 2. After $t_{l}$, the freewheeling diode stage starts with a reduction trend from an extremely high current value of 49 times more than the normal current (23-1146 A). Therefore, a fast fault detection scheme should detect the fault before MCT. In this paper, the values of $t_{o}$ and $t_{d}$ are assumed as $1 \mathrm{~ms}$. Fig. 8 presents the simulation results of the MM regional maxima output for fault current at $t=1$ with fault resistance of $0.05 \Omega$ at Line1 is shown. Based on this figure, MCT's value is $24 \mathrm{~ms}$, and starting the freewheeling diode stage is $25 \mathrm{~ms}$. Therefore, the fault should be detected within $24 \mathrm{~ms}$. Using the MM regional maxima, the value of this signal reaches its maximum value within $3.8 \mathrm{~ms}$, which shows the high speed of this method. Moreover, the peak time of fault current is $4 \mathrm{~ms}$, in which the detection time is less than this value.

Also, the value of $\xi$, in this case, is 0.0552 a $10^{-3}$, then the operation time after adding the selectivity term will be 4.24 ms. In Fig. 9, a LIF at L3 has occurred at $t=1$ with fault resistance of $0.2 \Omega$, and after detecting fault by MMbased fault detection function, the tripping signal is sent to the related SSCBs to isolate the fault. As shown in Fig. 9, since the value of $\xi$, in this case, is 0.112 a $10^{-3}$, the LIF is detected and isolated within $3.9 \mathrm{~ms}$ and $4.9 \mathrm{~ms}$, respectively, which is much fewer than the damaging time of converters. In Table 3, the results for different cases of LIFs are indicated. As can be seen, the LIF is detected within a time lower than the MCTs in all scenarios. Therefore, the proposed method guarantees the fast detection and isolation of LIFs. Moreover, the length of this scheme's utilized structural element is selected by considering MCT, which is 100 in this paper. The fault detection transferred signal is the current of the line.

In HIFs, Fig. 10 represents the simulation results of the MM-based fault detection output for HIF at $t=1$ with equivalent fault resistance of $4 \Omega$, and arc constant of 27000 at $\mathrm{Line}_{2}$ is shown. Based on this figure, this signal's value reached to peak immediately and oscillated every $40 \mu \mathrm{s}$. By utilizing the proposed fault detection method, the fault is detected after $1.04 \mathrm{~ms}$ and isolated by SSCBs within $2.04 \mathrm{~ms}$, which shows the high speed of this scheme, as shown in Fig. 11.

TABLE 2

\begin{tabular}{lll} 
FAULT CURRENT CHARACTERISTICS OF DIFFERENT FAULT TYPES AT LINE & \\
\hline \hline Fault resistance $(\Omega)$ & MCT $(\mathrm{ms})$ & Fault current magnitude $(\mathrm{A})$ \\
\hline 0.10 & 23 & 1146 \\
0.20 & 22 & 1060 \\
0.30 & 21 & 467 \\
0.40 & 21 & 355 \\
0.50 & 20 & 286 \\
\hline
\end{tabular}



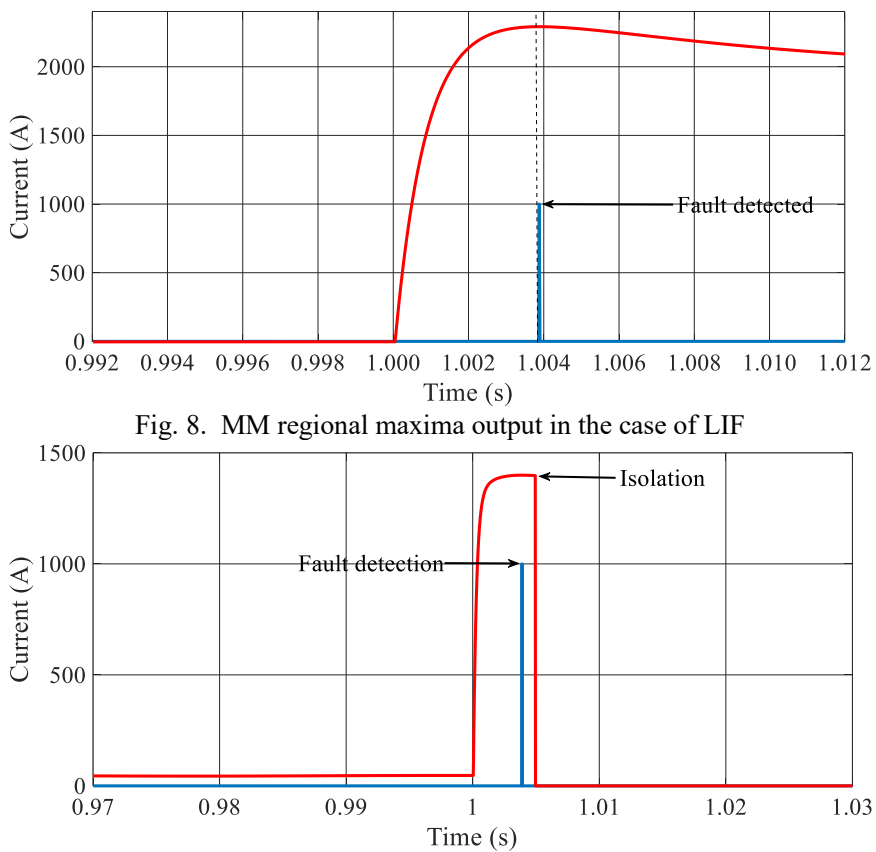

Fig. 9. The isolation of a LIF by utilizing the proposed relay

TABLE 3

FAULT CURRENT CHARACTERISTICS OF DIFFERENT LIF CONDITIONS

\begin{tabular}{cccc}
\hline \hline Fault location & Fault resistance $(\Omega)$ & MCT $(\mathrm{ms})$ & Isolation time $(\mathrm{ms})$ \\
\hline Line3 & 0.1 & 20 & 5.98 \\
Line3 & 0.3 & 20 & 4.54 \\
Line2 & 0.15 & 22 & 5.18 \\
Line1 & 0.35 & 21 & 1.80 \\
Line1 & 0.45 & 21 & 1.66 \\
\hline
\end{tabular}

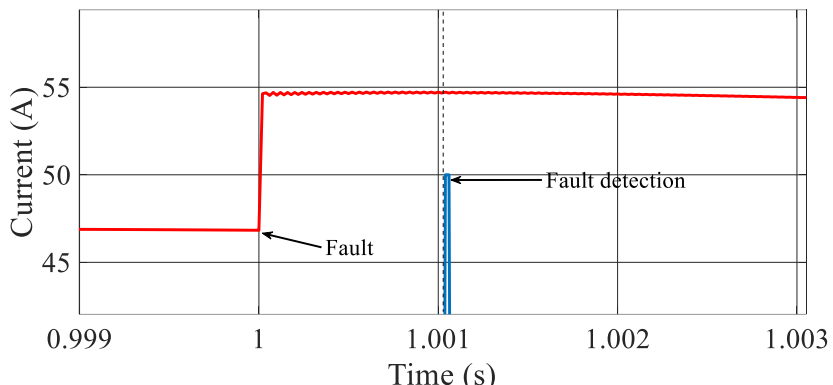

Fig. 10. Fault current and the fault detection signal during HIF

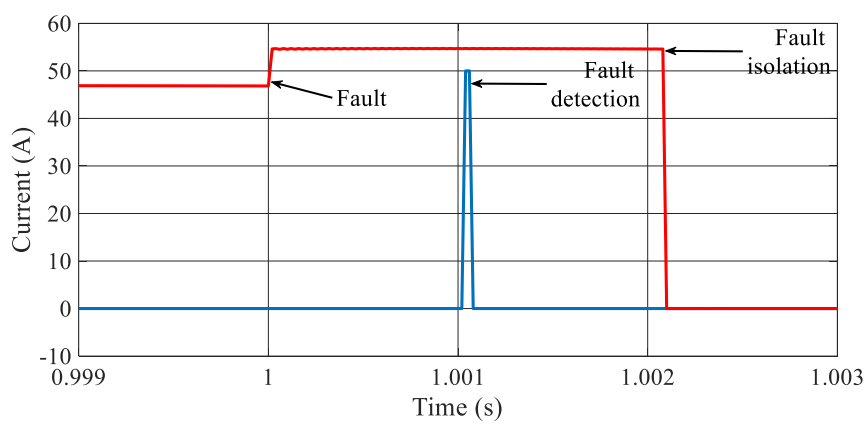

Fig. 11. Isolation of HIF by the proposed method

13 One the other hand, one of fault detection scheme challenges is distinguishing overload conditions and faults. 14 Besides, having noise in the measured value of current affects the effectiveness of the fault detection method. 
Therefore, an overloaded case is applied to the system, in which a $10 \mathrm{~kW}$ load is connected to the system at $t=0.996 \mathrm{~s}$, and a fault is occurred at $t=1 \mathrm{~s}$ with fault resistance of $0.95 \Omega$, as shown in Fig. 12 (a). The overload current in the presence of noise is shown in Fig. 12 (b). Based on Fig 12 (a), the fault detection method detects fault within 0.24 ms, without affecting by noise and overload.

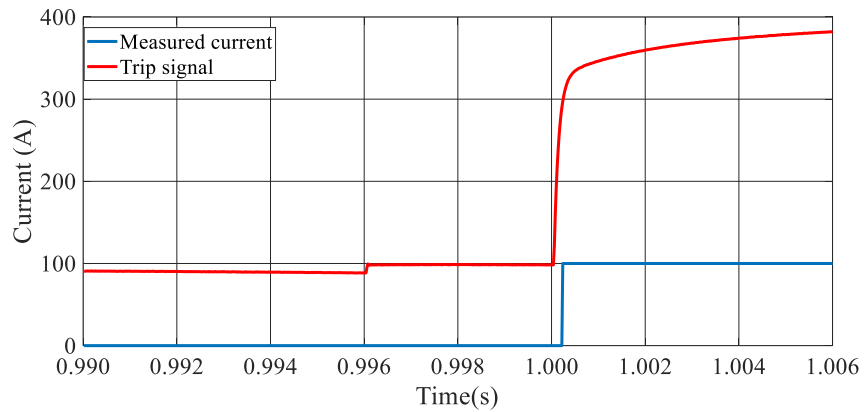

Another type of HIFs is no arcing faults, which are linear HIFs, and can be modeled by linear resistor. Therefore, the performance of the proposed method in linear HIFs is also evaluated to show the effectivity of the proposed fault detection scheme. As shown in Fig. 13, during the linear HIF, the current magnitude is increased approximately 10 A, and the fault, same as nonlinear HIF with the same magnitude, is detected within $1 \mathrm{~ms}$. Therefore, the proposed method is effective during both nonlinear and linear HIFs.

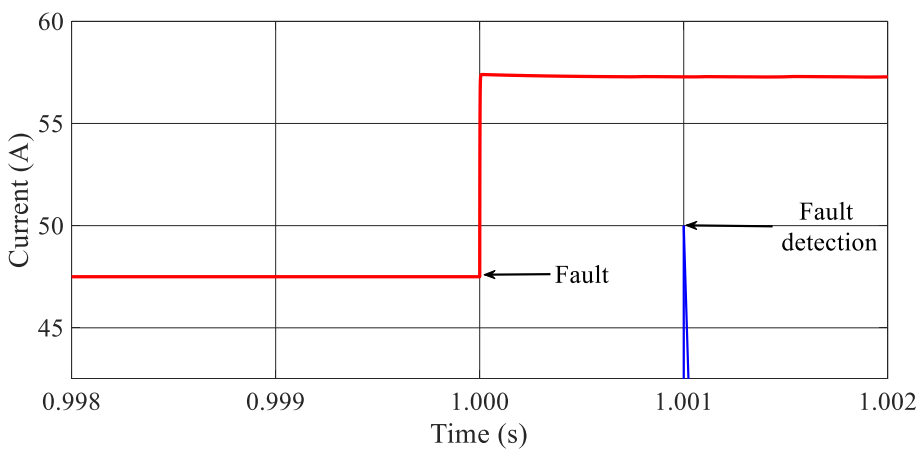

Fig. 13. Fault current and the fault detection signal during linear HIF

\section{B. Experimental results}

Various experimental tests were carried out with the scaled experiment system consists of power supply, converters, equivalent line segment, and dSPACE, as shown in Fig. 14. In this paper, LIF and HIF are applied to different line segment locations and measured by a current sensor at one side of the line with a sampling rate of $50 \mathrm{kHz}$. It should be noted that each power supply is equivalent to the output DC bus of a DC microgrid cluster. 
A LIF is occurred at $30 \%$ of the line from the relay side by fault resistance of $3.2 \Omega$. The current sensor measures the fault current, as shown in Fig. 15, and sends the measured values of line current to dSPACE, and the MM-based fault detection function is designed in the dSPACE environment. Therefore, within $2.18 \mathrm{~ms}$, the fault is detected, as shown in Fig. 16.

As shown in Fig. 15 and Fig. 16, the fault is detected less than peak time, which guarantees converter and freewheeling diodes' safety. After fault detection, the tripping signal sends to switches to isolate the line. As shown in Fig. 17, a LIF occurs at $60 \%$ of the line from the relay side by fault resistance of $3 \Omega$, which is detected within $2.10 \mathrm{~ms}$ and isolated by switches after $2.3 \mathrm{~ms}$ much fewer than the MCT. Based on the standard IEC-60909, the minimum fault current is defined based on a fault resistance, which increases the faulty line's current to a $20 \%$ increase in normal current. Therefore, in the under-study system, the fault resistance of $50 \Omega$ is considered maximum fault resistance.

On the other hand, to validate and prove the proposed method's efficiency during HIFs, a HIF fault is applied to the end of the line segment with fault resistance of $50 \Omega$, and the fault current waveform is shown in Fig. 18. Due to the nature of HIFs, the fault current reaches $1.2 \mathrm{~A}$, which the normal current is $0.9 \mathrm{~A}$. Then, the tripping signal is sent to the switches to isolate the faulty line, as shown in Fig. 18, which shows the line's isolating within $3.8 \mathrm{~ms}$.

In this paper, the results of fault detection and isolation proposed method for both LIFs and HIFs in a DC microgrid cluster are proposed. It is evident that the proposed method detects and isolates the faults within an extremely low operation time to avoid any damages to converters.

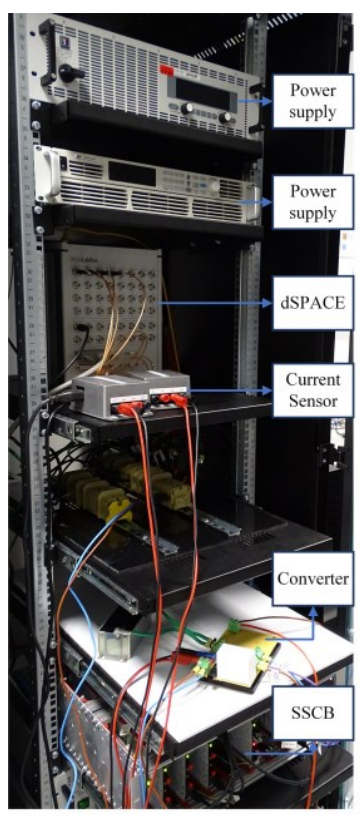

(a)

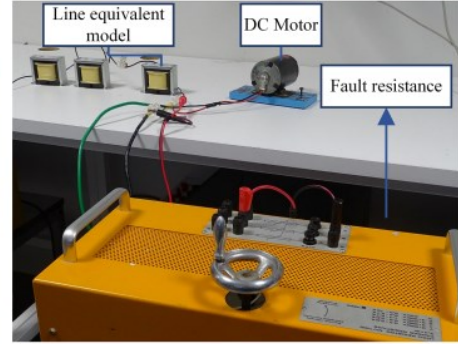

(b)

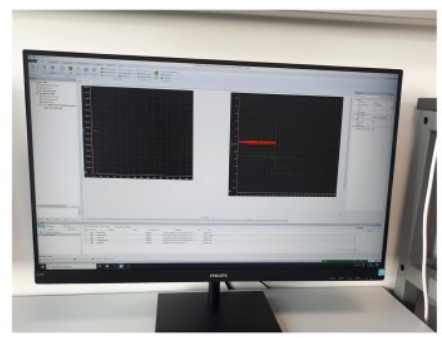

(c)

Fig. 14. The experimental test setup (a) power supplies, dSPACE, sensors, converter, SSCB, (b) loads, line, fault resistance (c) dSPACE interface 


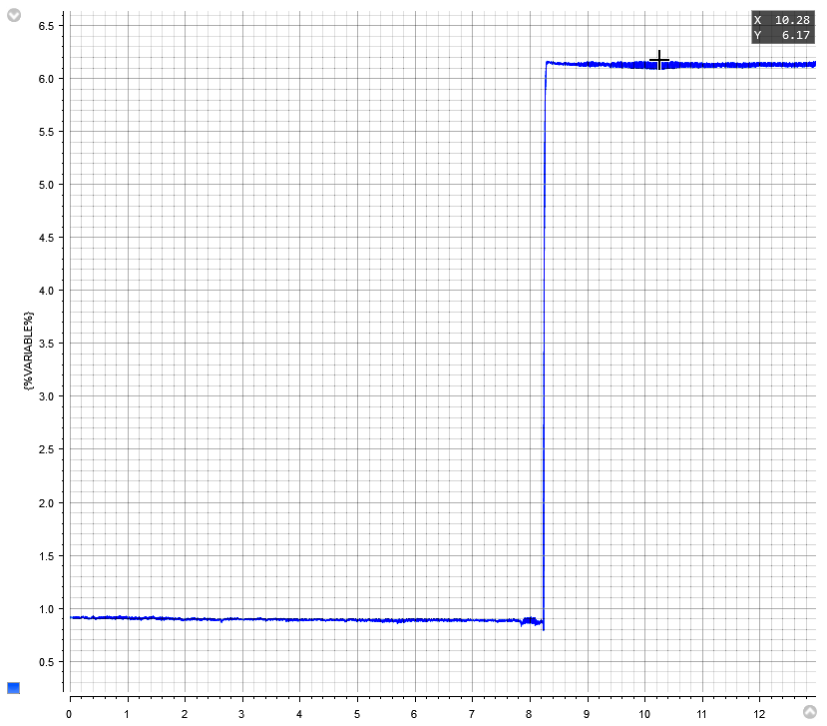

Fig. 15. The fault current waveform of a LIF
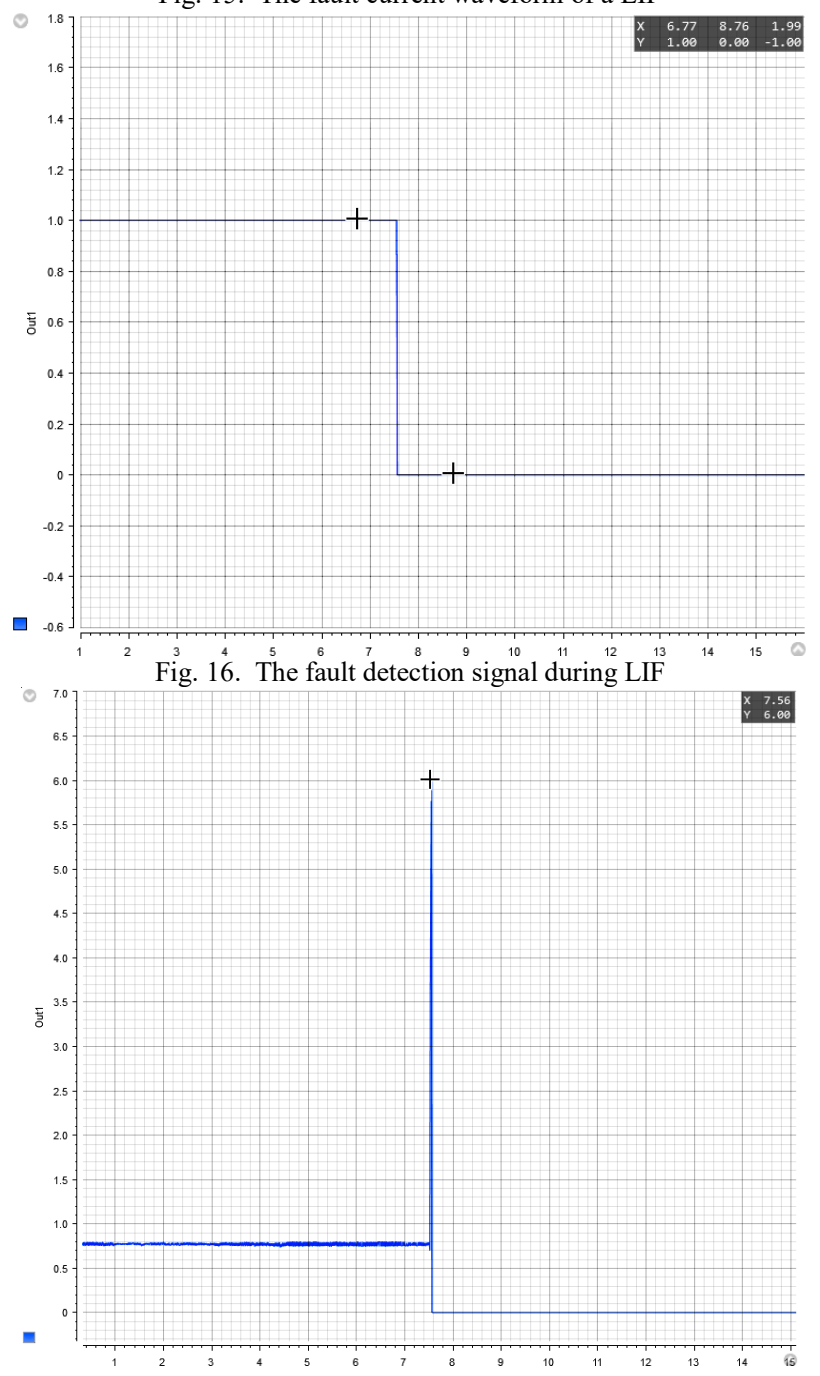

Fig. 17. The fault current waveform of LIF after 


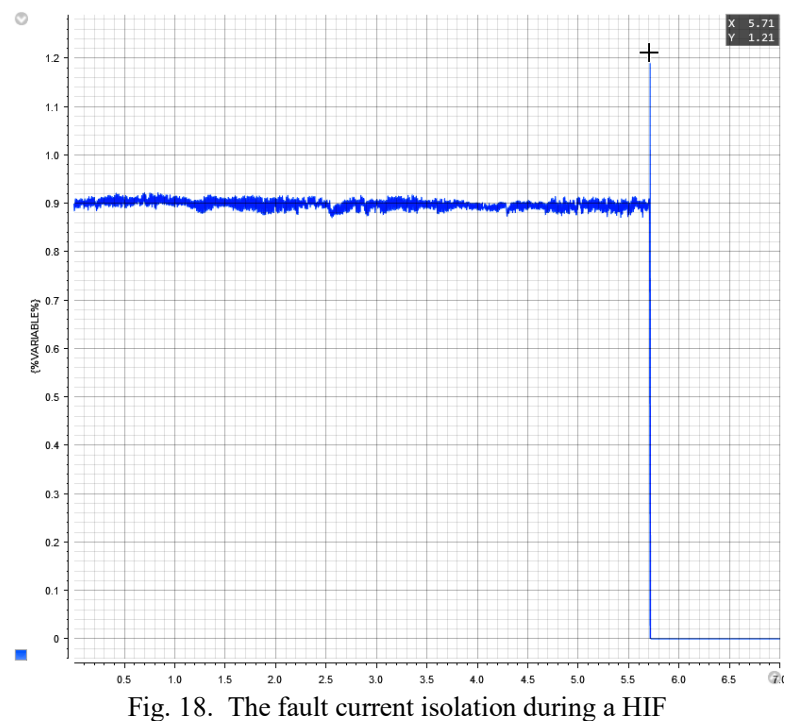

\section{Comparative analysis of the proposed method}

For emphasizing the efficiency of the proposed method, this method is compared with [32]-[34] in terms of fault detection time, ability to detect HIFs, and requiring communication facilities are compared and presented in Table 4. It should be noted that, due to the lack of enough protection scheme for the DC microgrid cluster, this method only compared with other fault detection methods for protecting DC microgrids.

In [32], a differential current based fault detection method is proposed. This method, due to the utilizing differential concept, requires communication links, and also the fault resistance is considered a limited value. In [33], a fault detection method for DC microgrids is suggested. This method requires only the data of current for one end of the line. However, this study does not consider the higher values of fault resistances than [34]. And the fault detection time of this method is not appropriate. In [34], the HIF detection of DC microgrids has not been considered on this method. However, this method does not require a communication link. An intelligent three tie switch is presented in [35] to detects HIF. However, this method requires a communication link, and the fault detection time is too high. In [36], a wavelet-based HIF detection method is suggested and does not require any communication links; however, it only applies to radial DC systems.

The proposed method in this paper only requires the measured information on one side, which reduces the cost, failure probability, noise, and delay. Moreover, this paper considers the HIFs with an accurate model of these DC faults. Besides, the fault detection's operation time is much fewer than other methods with less than $4 \mathrm{~ms}$.

Moreover, one of the aims of the proposed method is distinguishing HIFs and overloads during the noise. Therefore, in Fig. 19, the $d i / d t$ fault detection method [37] is compared with the proposed method during overload and HIFs under noisy conditions. As shown in Fig. 19, the $d i / d t$ method detects both overload and HIFs. However, the magnitude of di/dt of overload and HIF signals is approximately the same, $298 \mathrm{~A} / \mathrm{s}$ and $302 \mathrm{~A} / \mathrm{s}$, making it difficult to distinguish overload and HIF conditions. Moreover, the proposed MM fault detection scheme detects HIF $1 \mathrm{~ms}$ after $d i / d t$ method; however, by distinguishing HIFs and overloads, this amount of operation time is acceptable. On the other hand, as shown in Fig. 12 and 18, the proposed scheme only detects the HIFs, which shows the effectiveness and appropriate performance of the proposed scheme under different scenarios. 
TABLE 4

COMPARING OF PROPOSED METHOD WITH EXISTED METHODS

\begin{tabular}{|c|c|c|c|c|c|c|c|}
\hline Method & $\begin{array}{c}\text { Communication } \\
\text { link }\end{array}$ & Cost & $\begin{array}{l}\text { Detection } \\
\text { time }\end{array}$ & $\mathrm{HIF}$ & $\begin{array}{l}\text { Maximum fault } \\
\text { resistance }\end{array}$ & $\begin{array}{c}\text { Required } \\
\text { sampling rate }\end{array}$ & $\begin{array}{l}\text { Accurate model } \\
\text { of HIF }\end{array}$ \\
\hline$[32]$ & Yes & High & $110 \mathrm{~ms}$ & Not considered & $2 \Omega$ & $5 \mathrm{kHz}$ & No \\
\hline [34] & No & Low & $4 \mathrm{~ms}$ & Not considered & $8 \Omega$ & $10 \mathrm{kHz}$ & No \\
\hline [35] & Yes & High & $300 \mathrm{~ms}$ & Considered & $20 \Omega$ & Not mentioned & No \\
\hline
\end{tabular}

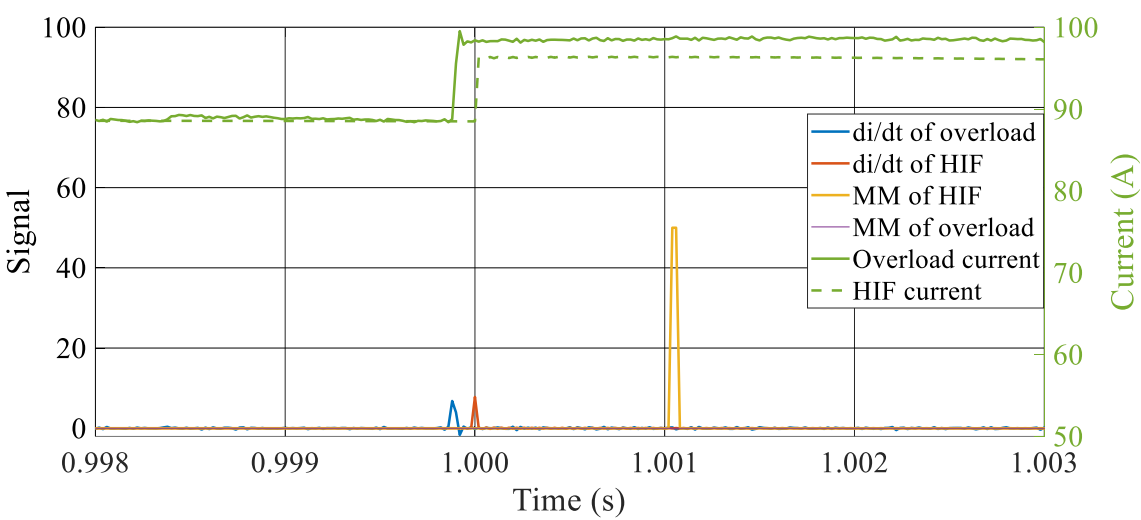

Fig. 19. Comparison of the proposed method with $\mathrm{di} / \mathrm{dt}$ method

\section{CONCLUSION}

An advanced local fault detection and isolation scheme is proposed in this paper to protect DC microgrid clusters against faults by using MM-based relays. An MM-based filter is used to eliminate the noises, and a MM regional maxima function is used to detect the LIFs and HIFs. The proposed scheme can provide a fast LIFs detection within a few milliseconds, thereby avoiding any damages to vulnerable converters during the high-rise fault current. It also can provide reliable detection of HIFs, which is difficult to detect due to the small changes of current. Due to the localized performance of the proposed scheme, this method can be considered an economical solution for protecting DC microgrid clusters. Moreover, a communication channel between relays and other components are not required in this strategy. The effectiveness of the proposed method has been validated in simulation and experimentally.

\section{REFERENCES}

[1] H.R. Baghaee, M. Mirsalim, G.B. Gharehpetian, and H.A. Talebi, "A decentralized power management and sliding mode control strategy for hybrid AC/DC microgrids including renewable energy resources," IEEE Trans. on Industrial Informatics, vol. PP, no. 99, pp. 1-10, March 2017, DOI: 10.1109/TII.2017.2677943.

[2] M.R. Habibi, H.R. Baghaee, T. Dragicevic, and F. Blaabjerg, "Detection of False Data Injection Cyber-Attacks in DC microgrids based on Recurrent Neural Networks, " IEEE Journal of Emerging and Selected Topics in Power Electronics, vol. PP, no. 99, pp. 1-18, January 2020, DOI: 10.1109/JESTPE.2020.2968243.

[3] N. Baran, and N. Mahajan, "Overcurrent protection on voltage-source-converter-based multiterminal DC distribution systems," IEEE Trans. on Power Delivery, vol. 22, no. 1, pp. 406-412, January 2007. 
[4] W. Liu, W. Gu, Y. Xu, Y. Wang, K. Zhang, "General distributed secondary control for multi-microgrids with both $p q$-controlled and droop-controlled distributed generators," IET Gen. Transm. Dist., vol. 11, no. 3, pp. 707-718, February 2017.

[5] X. Zhou, L. Zhou, Y. Chen, J.M. Guerrero, A. Luo, W. Wu, L. Yang, "A microgrid cluster structure and its autonomous coordination control strategy," International Journal of Electrical Power \& Energy Systems, vol. 100, pp. 69-80, September 2018.

[6] Peng C, Husain I, Huang AQ, Lequesne B, Briggs R. A fast mechanical switch for medium-voltage hybrid DC and AC circuit breakers. IEEE Transactions on Industry Applications. 2016 Mar 8;52(4):2911-8.

[7] Peng C, Song X, Huang AQ, Husain I. A medium-voltage hybrid DC circuit breaker -Part II: Ultrafast mechanical switch. IEEE Journal of Emerging and Selected Topics in Power Electronics. 2016 Oct 13;5(1):289-96.

[8] Hernandez JC, Sutil FS, Vidal PG. Protection of a multiterminal DC compact node feeding electric vehicles on electric railway systems, secondary distribution networks, and PV systems. Turkish Journal of Electrical Engineering \& Computer Sciences. 2016 Apr 15;24(4):3123-43.

[9] S.D.A. Fletcher, P.J. Norman, S.J. Galloway, G.M. Burt, "Determination of protection system requirements for DC unmanned aerial vehicle electrical power networks for enhanced capability and survivability," IET Elect. Syst. Transp. Vol. 1, no. 4, pp. 137-147, December 2011.

[10] M.A. Zamani, T.S. Sidhu, A. Yazdani, "A protection strategy and microprocessor-based relay for low-voltage microgrids," IEEE Trans. on Power Delivery, vol. 26, no. 3, July 2011.

[11] Bayati N, Hajizadeh A, Soltani M. Protection in DC microgrids: a comparative review. IET Smart Grid. 2018 Oct 18;1(3):66-75.

[12] P. Salonen, P. Nuutinen, P. Peltoniemi, J. Partanen, "LVDC distribution system protection: solutions, implementation and measurements," in Proc. $13^{\text {th }}$ European Conf. Power Electronics and Applications, Barcelona, Spain, Sep. 2009, p. 1-10.

[13] J. Wang, B. Berggren, K. Linden, J. Pan, "Multi-terminal DC system line protection requirement and high-speed protection solutions," in Proc. CIGRE Symposium, Cape Town, South Africa, 2015, p. 26-30.

[14] M. Ikhide, S.B. Tennakoon, H. Ha, A.L.Griffiths,S. Subramanian, A.J. Adamczyk, "A transient and non-unit-based protection technique for DC grids based on the rate-of-change (RoC) of the fault induced traveling-wave components," Sustainable Energy, Grids and Networks, vol. 1, no. 17, pp. 1-17, March 2019.

[15] M.A. Yaqobi, H. Matayoshi, M.S. Danish, M.E. Lotfy, A.M. Howlader, S. Tomonobu, "Low-Voltage Solid-State DC Breaker for Fault Protection Applications in Isolated DC microgrid Cluster," Applied Sciences, vol. 9, no. 4, pp. 723, Feb 2019.

[16] A. Meghwani, S.C. Srivastavafilters and S. Chakrabarti, "A Non-unit Protection Scheme for DC microgrid Based on Local Measurements," IEEE Trans. on Power Delivery, vol. 32, no. 1, pp. 172-181, Feb. 2017.

[17] D. Tzelepis et al., "Single-Ended Differential Protection in MTDC Networks Using Optical Sensors," IEEE Trans. on Power Delivery, vol. 32, no. 3, pp. 1605-1615, June 2017. 
[18] J.D. Park, J. Candelaria, "Fault detection and isolation in low-voltage dc-bus microgrid system," IEEE Trans. Power Delivery, vol. 28, no. 2, pp. 779-787, 2013.

[19] M. Michalik, W. Rebizant, M. Lukowicz, S.J. Lee, S.H. Kang, "High-impedance fault detection in distribution networks with use of the wavelet-based algorithm," IEEE Trans on Power Delivery, vol. 21, no. 4, pp. 1793-1802, October 2006.

[20] F. Ghalavand, B.A. Alizade, H. Gaber, H. Karimipour, "Microgrid islanding detection based on mathematical morphology," Energies, vol. 11, no. 10, pp. 2696, Oct 2018.

[21] H. Yong, C. Minyou, and Z. Jinqian, "High impedance fault identificationmethod of the distribution network based on discrete wavelet transforma-tion,” inProc. Int. Conf. Elect. Control Eng., 2011, pp. 2262-2265.

[22] M. Michalik, M. Lukowicz, W. Rebizant, S. Lee, and S.-H. Kang, "NewANN-based algorithms for detecting HIFs in multigrounded MV net-works,’IEEE Trans. Power Del., vol. 23, no. 1, pp. 58-66, Jan. 2008.

[23] M. J. B. Reddy, D. V. Rajesh, P. Gopakumar, and D. K. Mohanta, "Smartfault location for smart grid operation using RTUs and computationalintelligence techniques,’IEEE Syst. J., vol. 8, no. 4, pp. 1260-1271,Dec. 2014

[24] E. Guillén-García, L. Morales-Velazquez, A.L. Zorita-Lamadrid, O. Duque-Perez, R.A. Osornio-Rios and R.d.J. Romero-Troncoso, "Accurate identification and characterization of transient phenomena using wavelet transform and mathematical morphology," IET Gen., Transm. \& Dist., vol. 13, no. 18, pp. 4021-4028, Sep 2019.

[25] J. Yang, J. Edward Fletcher, J. O'Reilly, "Multiterminal DC wind farm collection grid internal fault analysis and protection design,“" IEEE Trans. on Power Delivery, vol. 25, no. 4, pp. 2308-2318, Oct. 2010.

[26] R. Hu, J. Wang, A. R. Mills, E. Chong, and Z. Sun, "Detection and Classification of Turn Fault and High Resistance Connection Fault in Permanent Magnet Machines based on Zero Sequence Voltage," IEEE Trans. on Power Electronics, vol. 35, no. 2, pp. 1922-1933, February 2020.

[27] Li J, Kohler JL. New insight into the detection of high-impedance arcing faults on DC trolley systems. IEEE Transactions on industry applications. 1999 Sep;35(5):1169-73.

[28] P. Maragos, R. Schafer, "Morphological filters - part i: their set-theoretic analysis and relations to linear shiftinvariant filters," IEEE Trans. on Acoust Speech Signal Process, vol.35, no. 8, pp. 1153-1169, August 1987.

[29] G. B. De Natale and G. Boato, 'Detecting morphological filtering of binary images ,'IEEE Trans. Inf. Forensics Security, vol. 12, no. 5,pp. 1207-1217, May 2017.

[30] S. Gautam, S.M. Brahma, "Overview of mathematical morphology in power systems - a tutorial approach," in Proc. IEEE Power Engineering Society General Meeting, Calgary, Canada. 2009. p. 1-7.

[31] Park JD, Candelaria J, Ma L, Dunn K. DC ring-bus microgrid fault protection and identification of fault location. IEEE transactions on Power delivery. 2013 Jul 2;28(4):2574-84.

[32] S. Dhar, R. K. Patnaik and P. K. Dash, "Fault Detection and Location of Photovoltaic Based DC microgrid Using Differential Protection Strategy," IEEE Trans. on Smart Grid, vol. 9, no. 5, pp. 4303-4312, September 2018. 
1 [33] P. Cairoli and R. A. Dougal, "Fault Detection and Isolation in Medium-Voltage DC microgrids: Coordination Between Supply Power Converters and Bus Contactors," IEEE Trans. on Power Electronics, vol. 33, no. 5, pp. 4535-4546, May 2018.

4 [34] Y.M. Yeap, N. Geddada, K. Satpathi, and A. Ukil, "Time and Frequency Domain Fault Detection in VSC

[36] D. K. J. S. Jayamaha, N. W. A. Lidula and A. D. Rajapakse, "Wavelet-Multi Resolution Analysis Based ANN Architecture for Fault Detection and Localization in DC Microgrids," in IEEE Access, vol. 7, pp. 145371-145384, 2019.

[37] Yeap YM, Geddada N, Ukil A. Capacitive discharge based transient analysis with fault detection methodology in DC system. International Journal of Electrical Power \& Energy Systems. 2018 Apr 1;97:127-37. 